\title{
Influence of Vinyl Acetate-Versatic Vinylester Copolymer on the Microstructural Characteristics of Cement Pastes
}

\author{
Carlos Eduardo Marmorato Gomes ${ }^{\mathrm{a} *}$, Osny Pellegrino Ferreira ${ }^{\mathrm{b}}$, Mauro Roberto Fernandes $^{\mathrm{c}}$ \\ ${ }^{a}$ Department of Science and Engineering of Materials, University of São Paulo \\ ${ }^{\mathrm{b}}$ School of Engineering of São Carlos, University of São Paulo, Brazil \\ 'Institute of Chemistry of São Carlos, University of São Paulo
}

Received: September 3, 2004; Revised: January 18, 2005

\begin{abstract}
To understand the principles of polymer modification and its interference in the formation of some phases of Portland cement composites, several techniques are adopted such as Fourier Transform Infrared Spectroscopy and Thermogravimetric Analysis. In this study, these techniques were adopted to verify the influence of VA/VeoVA copolymer in seven pastes of high-early-strength portland cement twenty-eight days old, being four pastes with different polymer content and the same water/cement ratio, and the other three with extra water content increased by polymer content. In addition, scanning electronic microscopy was employed to verify the formation of copolymer film. The results showed possible interaction between acetate anion from the partial hydrolysis of copolymer and $\mathrm{Ca}^{++}$ion from $\mathrm{C}_{2} \mathrm{~S}$ and $\mathrm{C}_{3} \mathrm{~S}$ hydration. Moreover, the magnitude of the decrease of portlandite formation is directly affected by water/cement ratio. By SEM analyses, the formation of two matrices, being one organic and the other inorganic, was also observed.
\end{abstract}

Keywords: cement paste, thermogravimetric analysis, infrared spectroscopy, VA/VeoVA

\section{Introduction}

The polymer application in portland cement composites is not new and the concept of the polymer modification has been researched for the past 75 years or more. In the last 30 years, several publications have shown the benefit of the polymer addition in the properties of the portland cement composite such as strength, deformability, adhesion, waterproofness and durability ${ }^{1-3}$.

There are several kinds of polymeric compounds for applications in concretes such as the polymer latex, redispersible polymer powder, water-soluble polymer and liquid polymer ${ }^{2-4}$. Because of the easy application ${ }^{3}$, the redispersible polymers are commonly used in the composites, being the most important the poly(ethylene-vinyl acetate)-EVA, the poly(styrene-acrylic ester) - SAE, the polyacrylic ester - PAE and the poly(vinyl acetate-vinyl versatate) - VA/VeoVA applied in this study.

To understand the interference of polymer modification in the formation of some phases of portland cement composite, several techniques have been adopted such as the thermogravimetric analysis, which is also used in several studies to determine the amount of the pozzolanic reaction and the hydration of cement pastes by estimating $\mathrm{Ca}(\mathrm{OH})_{2}$ content and calcium hydrates content. Calcium hydroxide, being one of the major phases in hydrated portland cement, occupies about $20 \%$ to $25 \%$, by volume, of the total mass and is produced by hydration of tricalcium silicate and dicalcium silicate phases. The importance of this phase is due to its prominent role in the cement paste. Although extensive studies have been directed towards the cement paste, much less attention has been paid towards the polymer modified mortars, especially those modified with powdered emulsions and aqueous polymer dispersions ${ }^{5}$.

\section{Literature Review}

\subsection{Polymer-based admixtures}

The concept of polymer modification in not new and the first patent

*e-mail: marmorato@itelefonica.com.br was obtained in 1923. This patent refers to the use of cement as filler in polymer matrix. In 1924, the first patent was published using the concept of polymer modification for cement mortar and concrete ${ }^{2-4}$.

Basically, there are three kinds of polymer-based admixtures also called cement modifiers: polymer-modified mortar (PMM) and concrete (PMC); polymer mortar (PM) and concrete (PC); and polymer-impregnated mortar (PIM) and concrete (PIC).

As a principle of polymer modification, it is very important that both cement portland hydration and polymer film formation proceed well in order to produce a monolithic matrix phase with a network structure in which the cement hydrate phase and polymer phase interpenetrate. The modification with redispersible polymer powders, as the modification with VA/VeoVA used in this study is similar to that of latex formation except that it also involves the redispersion of the polymer powders. In these cases, the modification is governed by both cement portland hydration and polymer film formation processes in their binder phase. The cement hydration process generally precedes the polymer film formation by coalescence of polymer particle.

There are two theories for the mechanism of action of polymers in mortars and concretes. According to the first theory there is no interaction between the polymer and concrete. During hydration the hydrophilic part of the polymer is oriented towards the water phase whereas the hydrophobic part heads towards the air phase (pores and capillaries not pilled with water). Upon drying, the water is taken away, the hydrophobic particles coalesce together and form film. The other theory is that some chemical reactions may take place between the particle surfaces of reactive polymers, such as polyacrylic esters (PAE) and calcium ions $\left(\mathrm{Ca}^{2+}\right), \mathrm{Ca}(\mathrm{OH})_{2}$, solid surfaces or silicate surfaces over the aggregates. This creates a type of reinforcement in the concrete and produces semipermeable membranes ${ }^{1}$.

\subsection{Thermogravimetry analyses and FT-IR}

To investigate the interaction between polymers and cement port- 
land hydrates, several techniques are being adopted such as thermal analysis, X-ray diffraction, scanning electron microscopy and Fourier transform infrared spectroscopy.

Thermal analysis is the term used to identify a group of methods and techniques in which a physical property of a substance is measured as a function of temperature. Thermogravimetry (TG) and derivative thermogravimetry (DTG) have proven to be an invaluable tool for evaluating the nature of hydration products according to different stages of cement hydration, as well as to quantify the different phases ${ }^{1,6-9}$.

When cement is hydrated its main components are transformed into hydration products, mainly calcium silicate hydrates (C-S-H gel) and portlandite. The hydration rate of cement can be evaluated by measuring the mass loss of hydrated compounds up to $800{ }^{\circ} \mathrm{C}$. Some DTG peaks or temperature range have been reported when hydrated cement is heated in thermobalance ${ }^{7}$ :

- $100{ }^{\circ} \mathrm{C}$ : dehydration of pore water;

- $100{ }^{\circ} \mathrm{C}$ : $-300{ }^{\circ} \mathrm{C}$ : different stages of C-S-H dehydration;

- $\sim 500{ }^{\circ} \mathrm{C}$ : dehydroxylation of $\mathrm{Ca}(\mathrm{OH})_{2}$;

- $\sim 700{ }^{\circ} \mathrm{C}$ : decarbonation of $\mathrm{CaCO}_{3}$.

On the other hand, FT-IR is one of the powerful techniques normally used for molecular characterization. Recently, FT-IR has been found to be very useful in delineating the complex chemistry involved in the hydration of cement. In particular, the FT-IR results have been used to resolve the hydroxyl bands, to understand the degree of silicate polymerization occurring, and to monitor the dynamics of changes in the sulfate region during hydration reactions. Also, the effect of atmospheric carbon dioxide on hydration has been characterized ${ }^{10}$.

As explained above, polymer modification reduces the quantity of $\mathrm{Ca}(\mathrm{OH})_{2}$ formed in the mortars 5 . This work reports results of investigations in which methods of thermal analysis and FT-IR were applied to evaluate the effects of copolymer modification on the hydration process and the possible interaction between copolymer and Portland cement respectively.

\section{Experimental}

\subsection{Materials}

The materials employed for paste preparation were high-earlystrength portland cement (CP-V type according to Brazilian standards NBR-5733 and NBR-5737) and redispersible polymer VA/VeoVA. Characteristics of these materials are shown in Tables 1 and 2.

\subsection{Procedures}

The compositions established are shown in Table 3 . To verify the influence of water/cement ratio, the range was formed by four pastes with different polymer content (A-0\%; B-10\%; C-20\% e D-40\%)

Table 1. Chemical analyses of portland cement.

\begin{tabular}{lrrrr}
\multicolumn{5}{l}{ Four chemical analyses of high-early-strength portland cement (\%) } \\
\hline $\mathrm{SiO}_{2}$ & 19.55 & 19.40 & 19.47 & 19.64 \\
$\mathrm{Al}_{2} \mathrm{O}_{3}$ & 4.98 & 5.00 & 5.04 & 5.09 \\
$\mathrm{Fe}_{2} \mathrm{O}_{3}$ & 3.08 & 3.00 & 3.01 & 3.00 \\
$\mathrm{CaO}$ & 64.84 & 64.68 & 64.66 & 64.85 \\
$\mathrm{MgO}$ & 0.60 & 0.65 & 0.59 & 0.63 \\
$\mathrm{SO}_{3}$ & 2.86 & 2.81 & 2.86 & 2.88 \\
$\mathrm{CO}_{2}$ & 2.50 & 2.50 & 2.05 & 1.98 \\
$\mathrm{~K}_{2} \mathrm{O}$ & 0.70 & 0.71 & 0.70 & 0.69 \\
$\mathrm{P.F}$ & 2.93 & 3.04 & 2.78 & 2.68 \\
Residue & 0.31 & 0.28 & 0.25 & 0.23 \\
\hline
\end{tabular}

by cement weight and the same water/cement ratio, and the other three (E-10\%; F-20\% e G-40\%) with extra water content increased by copolymer/cement ratio. The following procedure was employed for the mixing of pastes: (i) dry mixing of VA/VeoVA and cement in low-speed mechanical mixer; (ii) dry mixing flowing over water plus superplasticizer; (iii) paste mixing in low-speed mechanical mixer for $180 \mathrm{~s}$; (vi) casting in hermetic cylindrical flasks; (v) demoulding 24 hours after casting; (vi) dry cure was maintained at $75 \%$ relative humidity (RH) until 27 days old; (vii) preparation for thermogravimetric analysis and FT-IR at 28th day.

The preparation of powder was realized using agate crucible where the paste was triturated until particles size lower than $0,074 \mathrm{~mm}$. To verify the behavior of modified pastes in simulated conditions of their applications, no protection against carbonation was employed as observed in other similar studies ${ }^{5,12,13}$.

TG analyses were realized in the thermal analyzer TGA 951 containing TGA 2100 accessory. The experimental conditions were: air atmosphere ${ }^{5,12}\left(100 \mathrm{ml} \cdot \mathrm{min}^{-1}\right)$; heating rate $\left(10^{\circ} \mathrm{C} \mathrm{min}^{-1}\right)$; platinum top-opened crucible; specimens of approximately $7 \mathrm{mg}$.

FT-IR analyses were realized in the BOMEM FT-IR model MB-102 equipment, using $\mathrm{KBr}$ pallets in the proportion of $1 \mathrm{mg}$ of specimen:100 mg of $\mathrm{KBr}$, spectra range $4000-300 \mathrm{~cm}^{-1}$, and bands intensities expressed in transmittance (\% $\mathrm{T})$.

To study the microstructure, pieces were obtained from flexural tests to analyze the section of fracture. Before analyses, the specimens were also immersed in iso-propyl alcohol, cleaned by ultrasonic equipment, dried in vacuum for 24 hours and thinly coated with $\mathrm{Au}$. The images shown in this paper referring to paste B, and pure admixture of copolymer and $\mathrm{Ca}(\mathrm{OH})_{2}$, were obtained by an eletronic microscope LEO-440.

The analyses were realized in the Institute of Physics of São Carlos and in the Institute of Chemistry of São Carlos, University of São Paulo.

\section{Results and Discussion}

Table 3 shows the mixture proportions analyzed. Figures 1 and 2 show the thermogravimetric analyses; such results are shown in Table 4.

As seen in the figures, there is evidence that the presence of VA/VeoVA copolymer interferes with the behavior of the hydroxide

Table 2. Physical characteristics of VA/VeoVA copolymer.

\begin{tabular}{lc}
\hline \multicolumn{2}{c}{ Physical analyses } \\
\hline Solids content $(\%)$ & $99 \pm 1$ \\
Anti-blocking content $(\%)$ & $12 \pm 2$ \\
Apparent density $\left(\mathrm{g} / \mathrm{cm}^{3}\right)$ & 0.45 to 0.60 \\
Particle size $(\mu \mathrm{m})$ & $80 \pm 10$ \\
\hline
\end{tabular}

Table 3. Mixture proportions.

\begin{tabular}{ccccc}
\hline Composition & Cement & $\begin{array}{c}\text { additional } \\
\text { copolymer } \\
\text { content }(\%)\end{array}$ & $\begin{array}{c}\text { W/C } \\
\text { ratio }\end{array}$ & $\begin{array}{c}\text { water/ } \\
\text { (copolymer+ } \\
\text { cement) ratio }\end{array}$ \\
\hline A & 1 & 0 & 0.35 & - \\
B & 1 & 10 & 0.35 & - \\
C & 1 & 20 & 0.35 & - \\
D & 1 & 40 & 0.35 & - \\
E & 1 & 10 & - & 0.35 \\
F & 1 & 20 & - & 0.35 \\
G & 1 & 40 & - & 0.35 \\
\hline
\end{tabular}


calcium and its content (Table 4). Considering the weight loss in the figures, it is noted that the quantity of $\mathrm{Ca}(\mathrm{OH})_{2}$ is less than that unmodified mortar and it gradually decreased with the increase of the polymer content. These results are in line with those shown by the studies of reference 5, which employed similar proceedings.

As shown in the literature, the decrease of portlandite formation by addition of the cement modifiers can be both the consequence of lower cement hydration and a possible chemical interaction between groups from alkaline hydrolyses of polymers and hydration products of portland cement ${ }^{1,5,11-14}$. As shown in reference 11, some polymers that contain vinyl acetate group can suffer hydrolysis when dispersed in alkaline medium. The product of this hydrolysis is the acetate anion $\left(\mathrm{CH}_{3} \mathrm{COO}\right)^{-}$, which can react with $\mathrm{Ca}++$ ion from $\mathrm{C}_{2} \mathrm{~S}$ and $\mathrm{C}_{3} \mathrm{~S}$ hydration and form an organic salt (calcium acetate). Some evidence of this chemical interaction is also detailed in FT-IR analyses.

In this way, the decrease of portlandite formation in the cement pastes can also be attributed to chemical interaction between VA/ VeoVA and cement paste.

The formation of calcium acetate increases the loss weight of the carbonate phases ${ }^{11}$ as shown below:

$$
\mathrm{Ca}\left(\mathrm{CH}_{3} \mathrm{COO}\right)_{2} \text { (s) } \stackrel{\left(\sim 380^{\circ} \mathrm{C} \text { to } 400{ }^{\circ} \mathrm{C}\right)}{\longrightarrow} \mathrm{CH}_{3} \mathrm{COCH}_{3}(\mathrm{~g})+\mathrm{CaCO}_{3}(\mathrm{~s})
$$

This was not clearly observed in the results because of specimens carbonation and the lower degeneration of VeoVA based copolymers in alkaline environment.

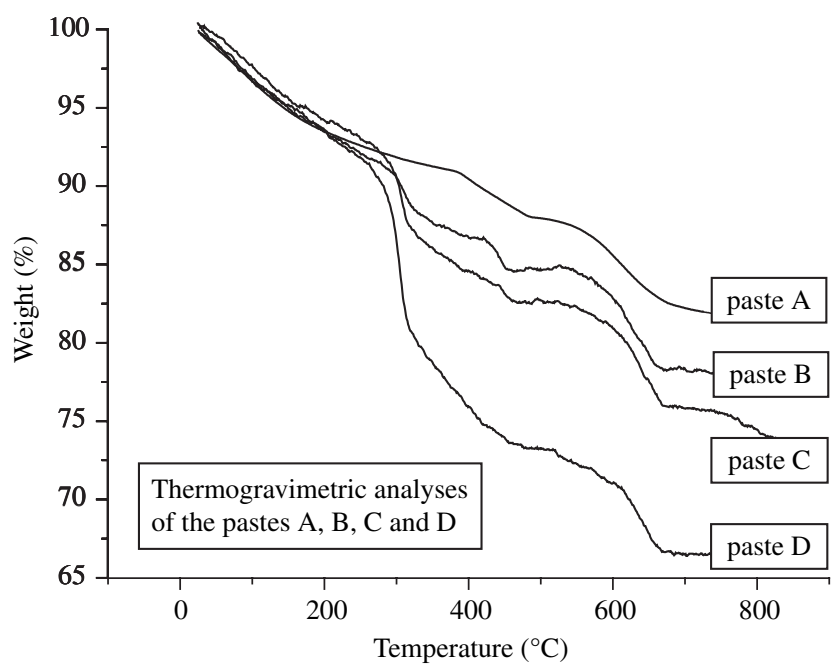

Figure 1. Influence of $\mathrm{Va} / \mathrm{VeoVA}$ content in the portland cement paste.
In addition, other possible fonts of carbonation can also occur during the mixing process. In this way, the calcium hydroxide dissolved in aqueous phase reacts with $\mathrm{CO}_{2}$ entrapped in the paste. Moreover, copolymers with film-forming capacity can improve the carbonation of portlandite in the paste since the film surface contains numerous air bubbles that carry $\mathrm{CO}_{2}{ }^{11,15}$.

On the other hand, although there are several fonts of carbonation, the results allow to conclude that the magnitude of the reduction of portlandite is directly affected by the polymer/cement ratio and the water/cement one.

According to literature ${ }^{5}$, some polymers may reduce the hydration at early ages. As previously illustred, the analyses of pastes E, F and $\mathrm{G}$ with extra water content showed the major quantity of $\mathrm{Ca}(\mathrm{OH})_{2}$ when compared with pastes $\mathrm{B}, \mathrm{C}$ and $\mathrm{D}$ respectively.

Figures 3 to 6 show the FT-IR spectrum of cement, VA/VeoVA copolymer and admixtures studied

Regardless of the presence of VA/VeoVA in the pastes, the following bands could be observed on the FT-IR spectrum: calcium hydroxide bands $\left(3642 \mathrm{~cm}^{-1}\right)$, combined and absorbed water of C-S-H, Afm, and Aft, phases (3440-3446 $\left.\mathrm{cm}^{-1}\right)$, molecular water (3440-3446 and $\left.1640-1645 \mathrm{~cm}^{-1}\right)$, carbonate phases (1424-1436, 874-880 and $\left.704-712 \mathrm{~cm}^{-1}\right)$, sulphates phases $\left(1116-1118 \mathrm{~cm}^{-1}\right)$, anhydrous calcium silicates $\left(920,526-536\right.$ and $\left.458-464 \mathrm{~cm}^{-1}\right)$ and calcium silicates (970$\left.986 \mathrm{~cm}^{-1}\right)$. Although it was possible to observe the infrared bands at $\left(1558-1568 \mathrm{~cm}^{-1}\right)$, which are characteristics of carboxylate anion from

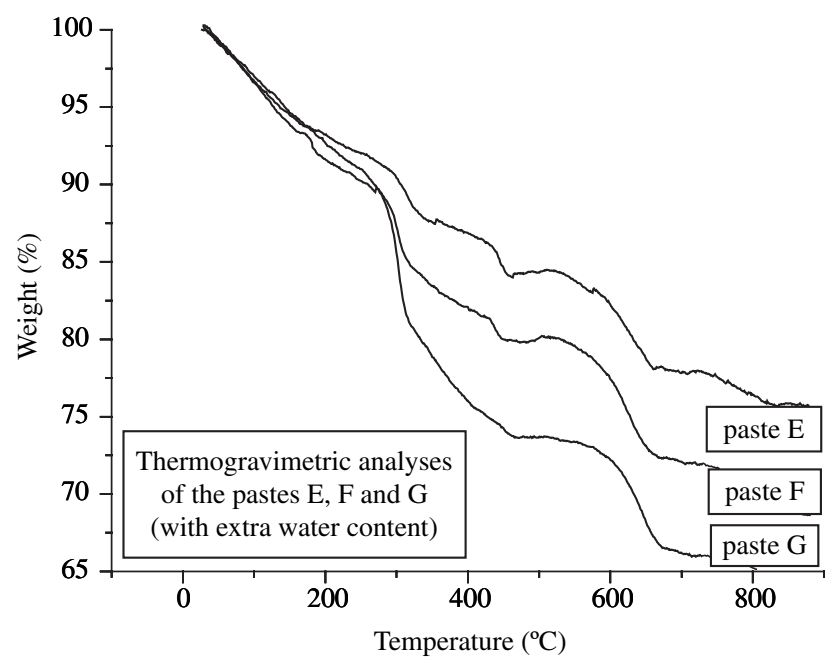

Figure 2. Influence of Va/VeoVA (with extra water content) in the portland cement paste.

Table 4. Results of the thermogravimetric analyses.

\begin{tabular}{|c|c|c|c|c|c|c|}
\hline \multirow[t]{2}{*}{ Mixture } & \multirow{2}{*}{$\begin{array}{c}\begin{array}{c}\text { Dehydration and } \\
\text { decomposition of } \\
\text { the } \mathrm{C}-\mathrm{S}-\mathrm{H}^{*}\end{array} \\
25{ }^{\circ} \mathrm{C} \sim 200{ }^{\circ} \mathrm{C}\end{array}$} & \multirow{2}{*}{$\begin{array}{l}\text { Decomposition of } \\
\text { the Polymer } \\
200{ }^{\circ} \mathrm{C} \sim 400{ }^{\circ} \mathrm{C}\end{array}$} & \multirow{2}{*}{$\begin{array}{l}\text { Decomposition of } \\
\text { the } \mathrm{Ca}(\mathrm{OH}) 2 \\
\text { (portlandite) }\end{array}$} & \multicolumn{2}{|c|}{$\begin{array}{l}\text { Decomposition of the } \\
\text { carbonate phases** }\end{array}$} & \multirow{2}{*}{$\begin{array}{l}\text { Residue } \\
\text { Above } \\
850^{\circ} \mathrm{C}\end{array}$} \\
\hline & & & & $500^{\circ} \mathrm{C} \sim 750^{\circ} \mathrm{C}$ & $700^{\circ} \mathrm{C} \sim 850^{\circ} \mathrm{C}$ & \\
\hline $\mathrm{A}$ & $6.540 \%$ & $0 \%$ & $2.928 \%$ & $6.423 \%$ & - & $81.56 \%$ \\
\hline $\mathrm{B}$ & $8.213 \%$ & $5.077 \%$ & $2.005 \%$ & $6.318 \%$ & $1.545 \%$ & $76.87 \%$ \\
\hline $\mathrm{C}$ & $5.822 \%$ & $9.608 \%$ & $2.075 \%$ & $6.690 \%$ & $2.141 \%$ & $73.67 \%$ \\
\hline $\mathrm{D}$ & $4.499 \%$ & $17.810 \%$ & $1.364 \%$ & $6.689 \%$ & - & $65.78 \%$ \\
\hline $\mathrm{E}$ & $7.965 \%$ & $4.993 \%$ & $2.642 \%$ & $6.146 \%$ & $2.381 \%$ & $75.67 \%$ \\
\hline $\mathrm{F}$ & $9.107 \%$ & $8.863 \%$ & $1.965 \%$ & $8.119 \%$ & $3.290 \%$ & $68.78 \%$ \\
\hline G & $8.770 \%$ & $15.960 \%$ & $1.650 \%$ & $7.715 \%$ & $1.854 \%$ & $64.07 \%$ \\
\hline
\end{tabular}

*calcium silicate hydrate

**different crystalline compounds ${ }^{16}$ 
partial hydrolysis of the vinyl acetate group, as previously written, the loss weight was not significant in the TG analyses and it could not be measured. These results were attributed to lower degeneration of VeoVA based copolymers in an alkaline environment rather than other copolymers that contain the vinyl acetate group.

VeoVA monomer has been very stable and it can be attributed to the protection of its ester bond by the Versatic group. Moreover, not only are its ester bonds shielded, so are the nearby vinyl acetate units. Up to $20 \%$ of VeoVA 10 incorporated into the polymer chain and a higher efficiency of copolymer in alkaline environment is expected. Other polymers, such as vinyl acetate and ethylene/vinyl acetate can easily hydrolyze and as a consequence, they can react with metallic

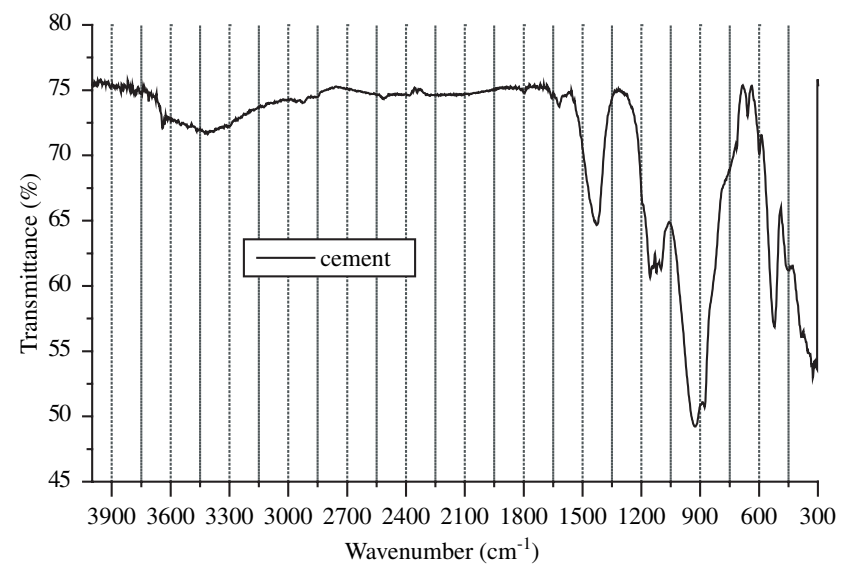

Figure 3. FT-IR spectrum of anhydrous Portland cement.
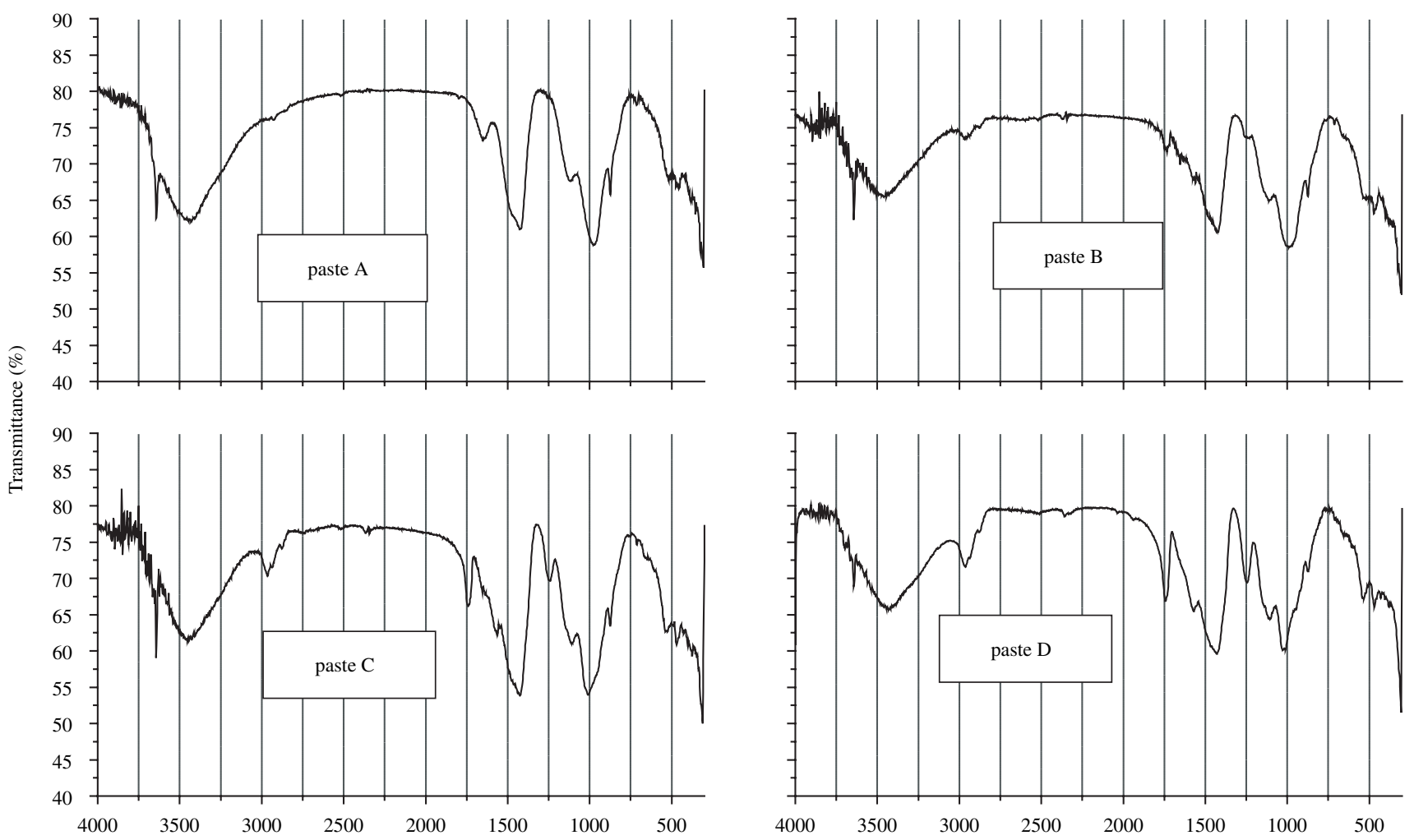

Wavenumber $\left(\mathrm{cm}^{-1}\right)$ cations from Portland cement ${ }^{11}$.

Tables 5 and 6 show the characteristic bands identification of Portland cement and copolymer respectively.

By the analyses of SEM, it was possible to observe the great adherence between VA/VeoVA copolymer and Portlandite from admixture of both pure materials (Figure 7).

As illustrated in Figure 8, for paste with addition of $10 \%$ of copolymer, it was already possible to observe the formation of copolymer film inside the cement matrix. Although this can be attributed to poor redispersion of the copolymer powder and lower water content, this reinforces the theory about the formation of two independent matrices, being one organic and the other one inorganic. Thus, the

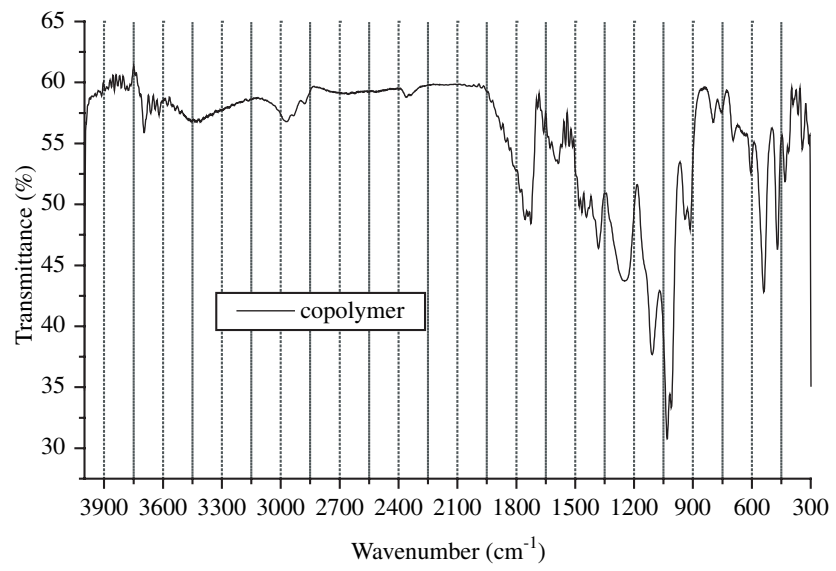

Figure 4. FT-IR spectrum of VA/VeoVA copolymer.

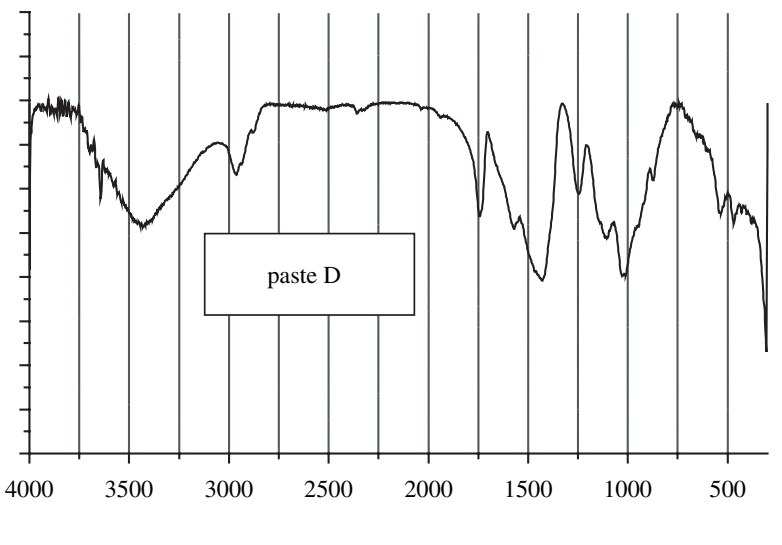

Figure 5. FT-IR spectrums of pastes A, B, C and D $(w / c=0.35)$. 


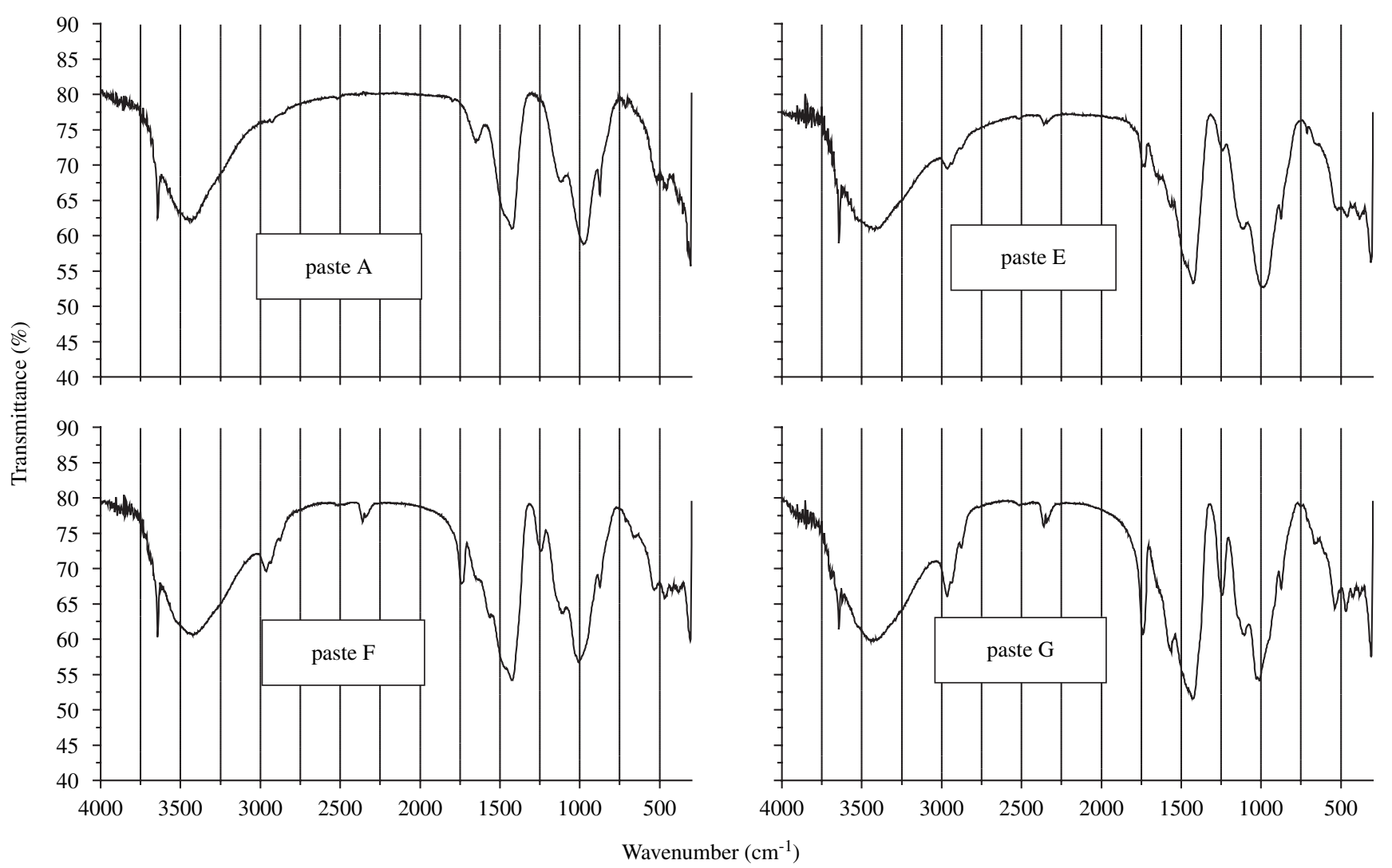

Figure 6. FT-IR spectrums of pastes A, E, F and G (w/(c+cop.) = 0.35).

Table 5. Characteristic bands of Portland cement paste.

\begin{tabular}{cc}
\hline \multicolumn{3}{c}{ Bands Identification of } \\
Portland cement \\
bands & group \\
3640 & $\mathrm{OH}$ \\
3402 & $\mathrm{~S}-\mathrm{O}$ \\
1622 & $\mathrm{~S}-\mathrm{O}$ \\
1426 & $\mathrm{CO}_{3}{ }^{2-}$ \\
1136 & $\mathrm{~S}-\mathrm{O}$ \\
920 & $\mathrm{Si}-\mathrm{O}$ \\
880 & $\mathrm{SiO} ; \mathrm{Al}-\mathrm{O} ; \mathrm{CO}_{3}{ }^{2-}$ \\
746 & $\mathrm{Al}-\mathrm{O}$ \\
712 & $\mathrm{CO}{ }_{3}^{2-}$ \\
660 & $\mathrm{~S}-\mathrm{O}$ \\
558 & $\mathrm{Si}-\mathrm{O}$ \\
522 & $\mathrm{Si}-\mathrm{O} ; \mathrm{Al}-\mathrm{O} ;$ \\
448 & $\mathrm{Si}-\mathrm{O} ; \mathrm{Al}-\mathrm{O} ;$ \\
\hline
\end{tabular}

results also confirmed the occurrence of physical interaction.

\section{Conclusions}

The TG curves obtained showed typical aspects of the portland cement mortar modified by polymer.

All curves showed the endothermal phenomena of the vaporization of the free water and decomposition of C-S-H from about $25^{\circ} \mathrm{C}$ to $200{ }^{\circ} \mathrm{C}$. The endothermic peaks between $400{ }^{\circ} \mathrm{C}$ and $500{ }^{\circ} \mathrm{C}$ are
Table 6. Characteristic bands of VA/VeoVA copolymer.

\begin{tabular}{cc}
\hline \multicolumn{3}{c}{ Bands Identification of } \\
VA/VeoVA \\
\hline bands & $\mathrm{Group}$ \\
3696 & $\mathrm{OH}$ \\
3620 & $\mathrm{CH}_{2}$ \\
$3380-3450$ & $\mathrm{OH}$ \\
2940 and 2864 & $\mathrm{CH}_{2} ; \mathrm{CH}_{3}$ \\
1740 & $\mathrm{C}=\mathrm{O}_{2}$ \\
1442 & $\mathrm{CH}_{2} ; \mathrm{CH}_{3 ;} \mathrm{CO}_{3}^{2-}$ \\
1378 & $\mathrm{C}-\mathrm{O}$ \\
1244 & $\mathrm{C}-\mathrm{O}$ \\
1102 & $\mathrm{C}-\mathrm{O} ; \mathrm{CH}_{3}$ \\
944 & $\mathrm{C}-\mathrm{C}^{2}$ in ester group \\
882 & $\mathrm{CO}_{3}^{2-}$ \\
748 & $\mathrm{CH}_{2} ; \mathrm{CO}_{3}^{2-}$ \\
630 & $\mathrm{OCO}^{2-}$ \\
606 & $\mathrm{C}-\mathrm{O}$ in ester group \\
540 & $\mathrm{C}=\mathrm{O}$ \\
\hline
\end{tabular}

due to the decomposition of portlandite. The decomposition of carbonate phases had occurred at about $500{ }^{\circ} \mathrm{C}$ and $850{ }^{\circ} \mathrm{C}$, being the phenomenon of this enlargement attributed to the formation of different crystalline compounds as shown in reference 16 .

VA/VeoVA copolymer does not cause important modifications in the spectral profile of modified pastes, excluding the possible inter- 


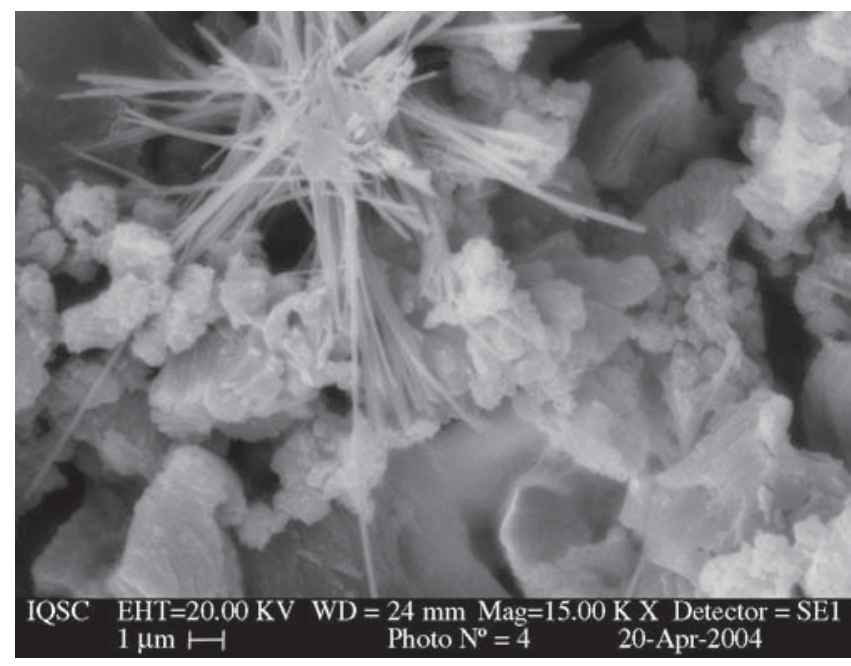

Figure 7. Adherence between VA/VeoVA film and Portlandite.

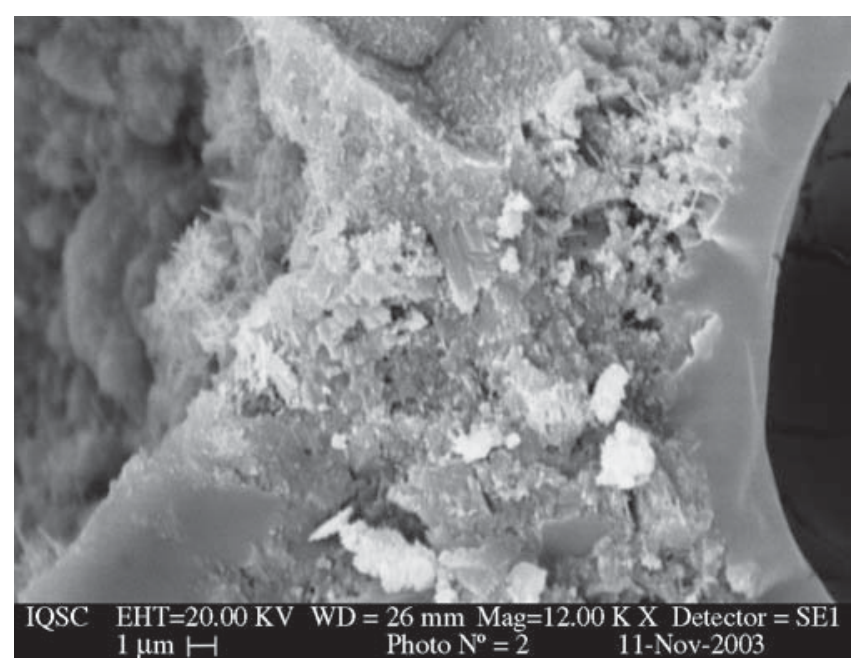

Figure 8. Interface between VA/VeoVA copolymer and Portland cement paste.

action between copolymer and portland cement. These results were attributed to lower degeneration of VeoVA based copolymers in an alkaline environment rather than other copolymers that contain the vinyl acetate group. The addition of VA/VeoVA copolymer strongly reduces the portlandite formation, being this result attributed to lower portland cement hydration.

The images of microstructure obtained by SEM suggest the formation of two different matrices, being one organic and the other one inorganic. As previously written, this allows us to suppose that during hydration, the hydrophilic part of the polymer is oriented towards the water phase whereas the hydrophobic part heads towards the air phase (pores and capillaries not pilled with water) and, upon drying, the water is taken away, the hydrophobic particles coalesce together and form film ${ }^{14}$.

\section{Acknowledgments}

The authors acknowledge the support of Rhodia Group and The Institute of Chemistry of São Carlos, University of São Paulo.

\section{References}

1. Chandra S, Flodin P. Interactions of polymers and organic admixtures on Portland Cement Hydration. Cement Concrete Research. 1990; 17: 975-890.

2. Ohama Y. Polymer-base admixtures. Cement and Concrete Composites. 1998; 20:189-212.

3. Ohama, Y. Recent Progress in Concrete-Polymer Composites. Advanced Cement Based Materials.1997; 5:31-40.

4. Fowler D. Polymers in concrete: a vision for the $21^{\text {st }}$ century. Cement and Concrete Composites. 1999; 21:449-452.

5. Afrid M, Ohama Y, Zafar M, Demura K. Behavior of $\mathrm{Ca}(\mathrm{OH})_{2}$ in polymer modified mortars. International Journal of Cement Composites and Lightweight Concrete. 1997; 11(4):235-244.

6. Dweck J, Buchler P, Coelho A, Cartledge F. Hydration of a Portland cement blended with calcium carbonate. Thermochimica Acta. 2000; 346:105-113.

7. Fordham C, Smalley I. A simple thermogravimetric study of hydrated cement. Cement and Concrete Research. 1985; 15:141-144.

8. Ollitrault-fichet R, Gauthier C, Calmen G, Boch P. Microstructural aspects in a polymer-modified cement. Cement and Concrete Research. 1998; 28(12):1687-1693

9. Tisivilis S, Kakali G, Chaniotakis E, Souvaridou A. A study on the hydration of Portland limestone cement by means of TG. Journal of Thermal Analysis. 1998;52:863-870.

10. Mollah M, Yu W, Schennach R, Cocke D. A Fourier transform infrared spectroscopic investigation of the early hydration of Portland cement and the influence of sodium lignosulfonate. Cement and Concrete Research. 2000; 30:267-273.

11. Silva D, Roman H, Gleize P. Evidences of chemical interaction between EVA and hydrating portland cement. Cement and Concrete Research. 2002; 32:1383:1390.

12. Vedalakshmi R, Raj A, Srinivasan S, Babu, K. Quantification of hydrated cement products of blended cements in low and medium strength concrete using TG and DTA technique. Thermochimica Acta. 2003; 407:49-60.

13. Gao J, Qian C, Wang B, Morino K. Experimental study on properties of polymer-modified cement mortars with silica fume. Cement and Concrete Research. 2002; 32:41-45.

14. Chandra S, Flodin P. Interactions of polymers and organic admixtures on portland cement hydration. Cement and Concrete Research. 1987; 17:875-890.

15. Janotka I, Madejova J, Stevula L, Frt'alova D. Behavior of $\mathrm{Ca}(\mathrm{OH})_{2}$ in the presence of the set styrene-acrylate dispersion. Cement and Concrete Research. 2000; 20:1-6.

16. Kasselouri V, Dimopoulos G, Parissakis, G. Decomposition of $\mathrm{CaCO}_{3}$ in the presence of organic acids. Cement and Concrete Research. 1995; 25:955-960. 